The present document is the final draft post-referring version of the paper. The corrected proof, post processed by the publisher, is accessible in via the journal webpage or at the following link:

http://www.sciencedirect.com/science/article/pii/S1755581716300190

doi:10.1016/j.cirpj.2016.04.008

Bertoni, A., Bertoni, M., Panarotto, M., Johansson, C., \& Larsson, T. C. (2016). Value-driven product service systems development: Methods and industrial applications. CIRP Journal of Manufacturing Science and Technology. 


\title{
Value-driven product service systems development: methods and industrial applications
}

\author{
Alessandro Bertoni ${ }^{\mathrm{a}^{*}}$, Marco Bertoni ${ }^{\mathrm{a}}$, Christian Johansson ${ }^{\mathrm{a}}$, Massimo \\ Panarotto ${ }^{\mathrm{a}}$, Tobias Larsson ${ }^{\mathrm{a}}$, \\ ${ }^{a}$ Department of Mechanical Engineering, Blekinge Institute of Technology, Karlskrona, \\ Sweden \\ *Corresponding author: \\ Alessandro Bertoni, Blekinge Institute of Technology, SE 37179, Tel: +46 0455-385502, Fax: +46 0455- \\ 385057,E-mail: alessandro.bertoni@bth.se \\ Marco Bertoni, Blekinge Institute of Technology, SE 37179, Tel: +46 0455-385533, Fax: +46 0455- \\ 385057,E-mail:marco.bertoni@bth.se \\ Christian Johansson, Blekinge Institute of Technology, SE 37179, Tel: +46 0455-385576, Fax: +46 \\ 0455-385057,E-mail: christian.m.johansson@bth.se \\ Massimo Panarotto, Blekinge Institute of Technology, SE 37179, Tel: +46 0455-385527, Fax: $+460455-$ \\ 385057,E-mail: massimo.panarotto@bth.se \\ Tobias Larsson, Blekinge Institute of Technology, SE 37179, Tel: +46 0455-385525, Fax: +46 $0455-$ \\ 385057,E-mail: tobias.larsson@bth.se
}

\begin{abstract}
In recent times a service-dominant logic is permeating the design of complex systems. However, in spite of their appeal, initiatives such as Product Service Systems (PSS) have not become mainstream, and methods are lacking to support this transition. This paper argues that methodological guidance, as well as tools for decision support, may be found in the research field of Value Driven Design (VDD), which originates in the realm of Systems Engineering. The paper objective is to elaborate on gaps and opportunities for cross-pollination between VDD and PSS. The results of a systematic review of methods and tools for design decision support highlight the opportunity for introducing optimization models derived from VDD in the PSS design process, while the latter can enrich VDD research with a more qualitative value assessment logic. The paper
\end{abstract}


summarizes this integration in a methodological approach, and exemplifies its application in case studies mainly from the aerospace and road construction equipment sector.

Keywords: Value Driven Design, Product-Service Systems, Preliminary Design, Systems Engineering, Engineering Design, Product Development, Servitization.

\section{Introduction and objectives}

A widespread servitization trend (Vandermerwe and Rada, 1989) has been observed among industrial companies acting in the global market. Complex development projects that were traditionally perceived as product centered, are today increasingly influenced by a service-dominant (S-D) logic, which suggests that the firm's offering is merely a proposition for the customer to realize at point of use (Vargo and Lush 2008). In the last decade, this logic has attracted worldwide interest from practitioners and researchers, spinning-off initiatives such as Product-Service Systems (PSS) (Goedkoop et al., 1999), Industrial Product Service Systems (IPS2) (Meier et al., 2010), Functional Products (Löfstrand et al. 2011) and Total Offers (Alonso-Rasgado et al., 2004). Lightfoot et al. (2013) highlight that large traditional manufacturing organizations, such as Alstom and ABB (Miller and Hartwick, 2002; Davies, 2004) or Rolls-Royce Aerospace (Harrison et al., 2006; Ng et al. 2012), have moved their position in the valuechain from product manufacturers to providing customers with "desired outcomes", by combining products and services. Not only this logic allows manufacturing companies to generate new revenue streams, to gain closer relationships with the customers (Ravald and Grönroos, 1996) and to increase operational performances to a level not reachable by mere hardware improvement (Mathieu, 2001), but also carries great potential to deliver designs that are sustainable while meeting essential needs (Roy 2000).

In spite of its appeal, recent research has shown that the application of a PSS approach remains limited (Vezzoli et al. 2015) and that servitization is often unsuccessful (Benedettini et al. 2015). PSS are not only complex to design, test, implement and bring to the mainstream (Vezzoli et al. 2015), but also represents a radical departure from a goods-dominant (G-D) logic, which is deeply entrenched in the mindset of equipment manufacturers ( $\mathrm{Ng}$ et al. 2012). Any interest to break this mindset faces the challenge of seeking methods and empirical research that could aid the transition.

This paper argues that the research field of Value Driven Design (Collopy and Hollingsworth 2011), which originates in the realm of Systems Engineering (SE), can provide methodological guidance, together with tools, to leverage the uptake of PSS design processes in industry. VDD collects methodologies that originate from George Hazelrigg's decision theory (1988) and that use the concept of "value" to manage the complexity and ambiguity of the SE design space. There are three main aspects that suggest drawing such parallelism. 
Firstly, both VDD and PSS research deal with the notion of 'complex systems', or at least with solutions that features a higher level of complexity than in traditional engineering. Complexity does not merely refer to number of parts in the product assembly. Rather, given the focus on value proposition, both VDD and PSS research embraces a broader definition that accounts for a complex network of suppliers and competencies (Tan 2010; Soban et al. 2011), characterized by a greater number of stakeholders and more heterogeneous value propositions.

Secondly, moving from the assumption that it is in the preliminary stages of design that the major part of a system value is committed (Ullman, 1992), both domains recognize the need to solve design trade-offs not merely looking at requirements, but rather actively using 'customer value' as metrics (for VDD see: Collopy and Hollingsworth 2011; for PSS see Qu et al. 2016). While this seems self-evident for VDD, a whole stream of research in the domain of PSS (Shimomura and Arai, 2009; Kimita et al., 2009; Vasantha et al. 2012; Cavalieri and Pezzotta, 2012) points to the need of understanding and evaluating 'customer value' in early stages of development.

Eventually, as shown by Cavalieri and Pezzotta (2012), most Service Engineering process models are based on the Royce's Waterfall model (Royce 1970) and on the Forsberg and Moog's (1999) "V-model", which means that VDD and most PSS processes share the same sequential step-by-step design process proposed by SE literature.

Building on such parallelisms, the purpose of the work is to bridge these two research streams. The objective of this paper is to identify, through a systematic literature review, opportunities for crosspollination between PSS design and VDD methodologies. The latter, which stems from the aerospace domain, has now reached a level of maturity that suggests expanding the application of its methods and tools towards PSS design. At the same time, mechanisms for value assessment that belong to a serviceoriented field may be introduced to support early stage decision making for complex systems. Emerging from this understanding, and from empirical research conducted in collaboration with Swedish manufacturing companies, the authors present an integrated Value-driven PSS design methodology. Here two types of value models, qualitative and quantitative, are applied in an iterative fashion to provide the necessary data to support early stage design decisions. Several case studies where such models have been applied in real cases are listed: the lessons learned from the implementations further indicate directions for future research.

\section{Theoretical framework}

\subsection{Product Service Systems design}

Complexity in product development is emphasized when hardware, software and services are packaged into a single 'total offer' (Alonso-Rasgado et al. 2004). Product-Service Systems (Mont, 2002) is one of the industrial trends representing the shift in manufacturers' strategic focus from selling a physical product to providing performance and availability, as a way to satisfy more sophisticated needs and expectations (Baines et al. 2007; Williams, 2007). Eight types of PSS are proposed by Tukker and Tischner (2006), which have been are further synthesized by Cook et al. (2006) in: 
- Product-oriented PSS: the ownership of the physical artifact is transferred to the customer and services are offered to ensure the "utility of the product", such as warranties and maintenance.

- Use-oriented PSS: the service provider retains the ownership of the physical artifact and the customer pays for its use over a period of time or units of service.

- Result-oriented PSS: the service provider, as in use-oriented PSS, retains the ownership rights of the physical artifact, and the customer pays a fee proportional to the expected outcome rather than for the mere usage of the product. For instance, instead of leasing a washing machine the customer can sign an agreement for receiving clean clothes through a washing service.

Compared to the traditional one-sale model, designing these PSS types challenges engineers to raise their awareness on customer and stakeholders needs along the entire product lifecycle, so to realize solutions that are value adding for all the actors involved (Isaksson et al. 2009). The need to integrate many domains (i.e., product development, service development, recycling, etc.) means for organizations to move "downstream" knowledge (from the later phases of the lifecycle) into the early phases of the design process (Jabbour and Santos 2008) and raises the demand for methods and strategies that support collaboration and cross-disciplinary integration in design (Morelli 2006; Jørgensen and al. 2006). A strategy to foster collaboration is to structure this knowledge in models: these shall enable design teams to play with the definition of design concepts, and to sort out the optimal combination of hardware and service that maximize the 'value' trade-off (Isaksson et al. 2015). However, how to build effective 'value models' to support trade-off activities and decision making in the early stages of PSS design is still an open question in literature (Isaksson et al. 2015)

\subsection{Value Driven Design}

Value Driven Design (VDD) (Collopy and Hollingsworth 2011) has become a popular umbrella term that collects several methodologies (O’Neill et al. 2010), ranging from previous work on Tradespace Exploration (Ross et al. 2004), to Value Centric Design (Brown and Emerenko 2008) and Value Driven Optimization (Castagne et al. 2009), and that is used by several research groups in the USA (O'Neill et al. 2010; Collopy and Hollingsworth 2011) and in Europe (Soban et al. 2011; Price et al. 2012; Monceaux et al. 2014) to indicate an "improved design process that uses requirements flexibility, formal optimization, and a mathematical value model to balance performance, cost, schedule, and other measures important to the stakeholders to produce the best possible outcome" (AIAA 2015).

The spirit of VDD is to avoid targeting "local optimal" solutions originating from the shortrange exploration of the design space around a baseline solution, which is typical of SE practices (Dahlgren, 2006). Rather, VDD attempts to open up the solution space for consideration by designers, systems engineers, program managers, and customers, by promoting quick what-if analyses that use a value function as metrics (Collopy and Hollingsworth 2011) to judge the "goodness of a design" (Cheung et al. 2012). The VDD methodology is explained as a number of iterative activities (Figure 1). 


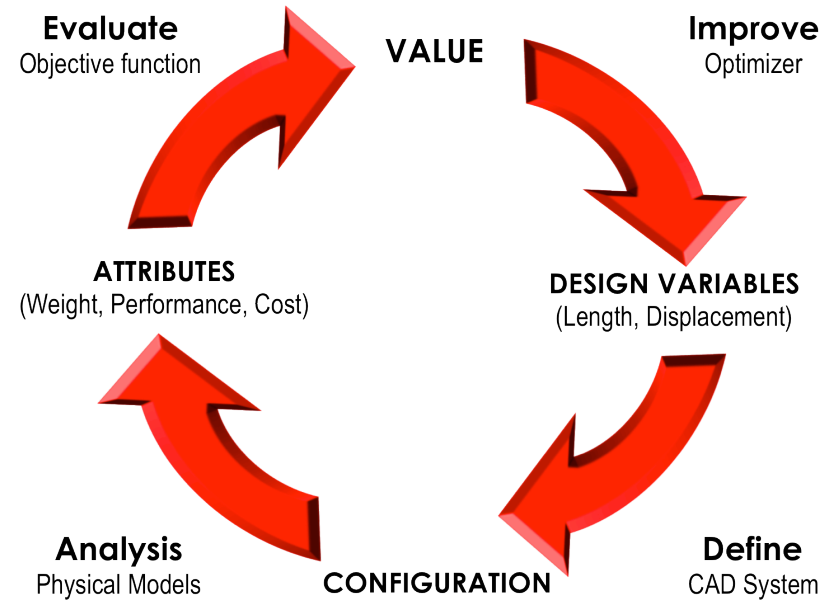

Figure 1: The Value Driven Design cycle (adapted from Collopy and Hollingsworth 2011)

As a first step (Improve), the design team picks a point in the design space at which to attempt a design. At the Design Variables step, this design is outlined and further elaborated into a detailed representation in the Define arc. In the Analysis arc, engineers produce a second description of the design instance, in the form of a vector of attributes. While the design variables are defined to make sense to the design engineers, the attributes are defined to connect to the customer. The Evaluate arc is what differentiates VDD from traditional SE, because the attributes are assessed by computing the value function (or objective function) rather than by observing how much a design complies with a given requirements list. The function renders a scalar score to any set of attributes of a product/service: if the current configuration renders a higher score than any previous attempts, the design team may it as its solution, or may try to produce an even better design by going around the cycle again.

A crucial activity in VDD is to determine the connections between a system's engineering attributes and the value function. Hence, the two most important parts of the model are: 1) how the customer makes revenue from the product (by the use of its main and additional functions) and 2) how the product causes the customer to incur costs (e.g., due to the presence of unwanted functions).

Quantification is normally performed by using monetary units ( $€$, SEK or US dollars), as they are perceived as the most intuitive metrics for value (Collopy and Hollingsworth 2011).

\section{Research context and methodology}

The research presented in this paper is the result of the concurrent research effort of the authors in different research projects. The overall framework for positioning VDD research in the context of PSS design was developed within the EU FP7 Collaborative \& Robust Engineering using Simulation Capability Enabling Next Design Optimisation (CRESCENDO) research project (EU Commission 2013). Research on the use of value models to support the early stages of PSS design has been further conducted within a Swedish funded research profile on Model Driven Development and Decision Support (MD3S)(bth-collaboration.se/) and on a Swedish funded research project named Virtual Turbine Module Demonstrator (VITUM) (http://www.bth.se/ing/pd.nsf/pages/vitum).

The research effort can be framed into the Design Research Methodology (DRM)(Blessing and Chakrabarti, 2009), which is a set of supporting methods and guidelines for engineering design research. 
The work presented in this paper describes the findings related to the Research Clarification (RC), Descriptive Study I (DSI), and Prescriptive Study (PS) phases of DRM. Participatory action research (PAR) (Whyte et al., 1989) and Case Study Research (Yin 1994) describe how the research was conducted in collaboration with the industrial partners along all stages of DRM.

$\mathrm{RC}$ activities featured semi-structured interviews with industrial practitioners from the partner companies. The main goal of this phase was to define the areas of investigation and the underlying objective of the study. Interviews were complemented by a preliminary literature review on the topic of VDD and PSS development.

DSI activities featured empirical observations of industrial practices. This phase gained benefit from multi-day company visits and from the part-time physical presence of researchers at the partners' industrial facilities. The PAR approach played a key role in collecting information and data to depict a comprehensive figure of the AS-Is situation. Furthermore the direct involvement of the researchers in the industrial practice and challenges has allowed to define an get access to a number of case studies linked to the development of decision support for the design of systems and components. The opportunity to observe different industrial contexts allowed the application of cross-case analysis (Eisenhardt, 1989; Schwandt et al., 2007) on the gathered empirical data. The analysis of the systematic literature review (described in detailed in section 2.1) further contributed the definition of the AS-IS situation during DSI.

PSI activities featured the development of a set of demonstrators for design decision support, which were implemented in the studies case and further analyzed with process owners and designers. PSI contributed to the further understanding of implications and opportunities related to the integration of VDD and PSS concepts. The comparison between available literature and empirical findings highlighted gaps and opportunities that have emerged during the frame of the projects,

Findings have been regularly presented in public forums; the feedback received from project managers and process owners at these events contributed to elaborate on their generalizability.

\subsection{Setup of the systematic literature review}

The investigation of academic and scholarly publications has initially followed a process of systematic review (Cook et al., 1997), which adopts the orthodox principles and generic framework articulated for the management science field (Tranfield et al., 2003). Systematic review was considered a logical choice to start with, not only because its transparency and replicability, but also because of its popularity in PSS research (see for instance: Lightfoot et al., 2013; Beuren et al. 2013; Reim et al. 2015; Cavalieri and Pezzotta 2012; Qu et al. 2016).

The objective of this review is to pinpoint how the concept of "value" is understood and interpreted in the fields of Engineering Design, Product Service Systems, Systems Engineering and Value Driven Design, when approaching early stage design decisions. Hence, the review was narrowed down only to those papers that explicitly refer to methods and tools for decision-making adopted in this stage of the design process. The scope was further limited to manufacturing companies. Such choice excluded those contributions focusing on software or information systems development, those dealing with development of business models either for PSS or SE, and those dealing with transitions or development 
of ontologies. Firstly, the systematic review served the purpose of providing answers and factual evidence to support the following three main hypotheses at the basis of the study:

- H1: The notion of "value" is trending in literature (overall).

- H2: The notion of "value" is trending in PSS design literature.

- H3: The notion of Value Driven Design is trending in SE literature and addresses service aspects.

Secondly, it points to the major approaches using value as driver to support decision making in preliminary design in both PSS and SE.

The review was initially conducted using the SCOPUS $^{1}$ database, because it is considered one of most exhaustive sources of multidisciplinary (i.e., including social science and engineering studies) peerreviewed literature (see: Geraldi et al., 2011), covering research from both major and minor publishers.

The combination of keywords used in the search queries is presented in Table 1. The reason for the selection of such keywords, and not more detailed ones, was to initially keep the sample data open and later proceed to a more accurate selection. This was done not to neglect important publications using more generic terminology in their description. The condition for the initial selection of the papers was that such keywords would need to appear at least once either in the title, in the abstract or as a keyword of the paper. Also, in order to include nearby terms (i.e., for operation: “operations", "operational”, etc.), the search has also been performed using abbreviations and the search operator *.

Table 1: Keywords combination in the systematic literature review, with number of hits

\begin{tabular}{|l|c|c|c|}
\hline Keywords used & Database hits & $\begin{array}{c}\text { Paper shortlisted on a } \\
\text { title and abstract base }\end{array}$ & $\begin{array}{l}\text { Paper added by } \\
\text { snowballing } \\
\text { techniques }\end{array}$ \\
\hline $\begin{array}{l}\text { Value + product service } \\
\text { systems + design }\end{array}$ & 214 & 41 & \\
\hline $\begin{array}{l}\text { Value Driven Design + } \\
\text { service OR operation* }\end{array}$ & $\begin{array}{c}27 \text { (of which two } \\
\text { already present in the } \\
\text { first query) }\end{array}$ & $\begin{array}{c}11 \text { (of which two } \\
\text { already present for the } \\
\text { first query) }\end{array}$ & \\
\cline { 1 - 2 } $\begin{array}{l}\text { Value + systems } \\
\text { engineering + service + } \\
\text { design }\end{array}$ & $\begin{array}{c}164 \text { (of which one } \\
\text { already present in the } \\
\text { second query) }\end{array}$ & $\begin{array}{c}8 \text { (of which one already } \\
\text { present in the second } \\
\text { query) }\end{array}$ & \\
\hline TOTAL & 402 & 57 & \\
\hline
\end{tabular}

Table 1 also presents the statistics related to the results of querying the SCOPUS database for different combinations of the selected search terms. In total, 402 papers have been identified in the search (after having removed redundant items). The following title-based and abstract-based filtering activity reduced the number of relevant hits down to 57. All these contributions have been further analysed, looking at the entire manuscript. Snowballing technique (Goodman, 1961) for cross-references was further applied to ensure completeness, and 11 additional publications were identified.

\section{Literature review results: statistical analysis and major trends}

Figure 2 shows the distribution of publications along the timeline (number of publications per year), providing a picture of how much the 'value' topic has been discussed in the engineering design, PSS and SE fields with regards to early design activities. The numbers show that the notion is trending in 
literature, and verify hypothesis $\mathrm{H} 1$.

\section{8}

16

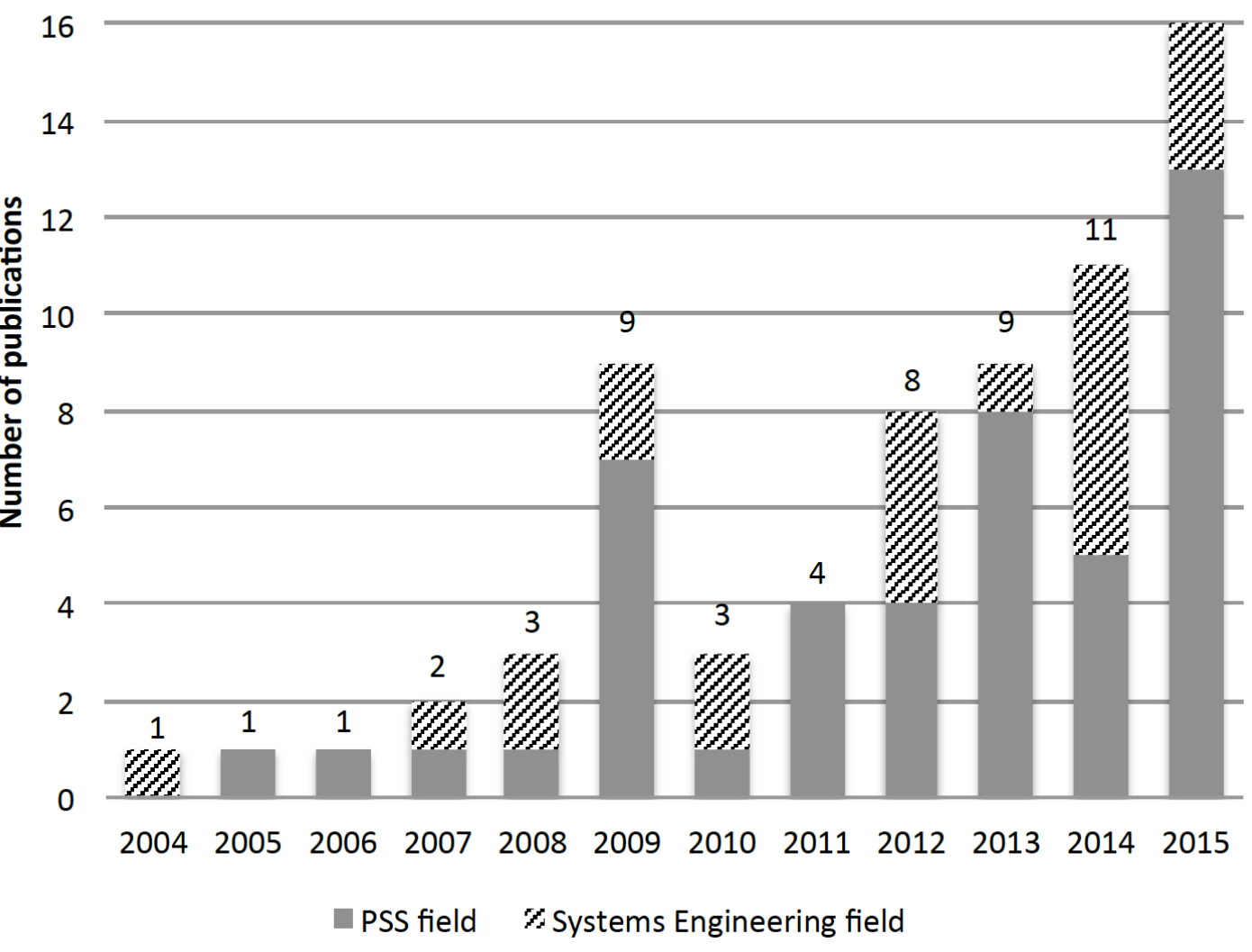

Figure 2. Overall distribution of the selected publications on a timeline (NOTE: partial data are used for year 2015)

More in detail, an increasing number of publications investigates aspects related to 'value' in the design of a PSS offer, with a focus on providing capabilities to assess it in a early design stage. Figure 3 shows the trend in number of publications, which verifies hypothesis $\mathrm{H} 2$. 


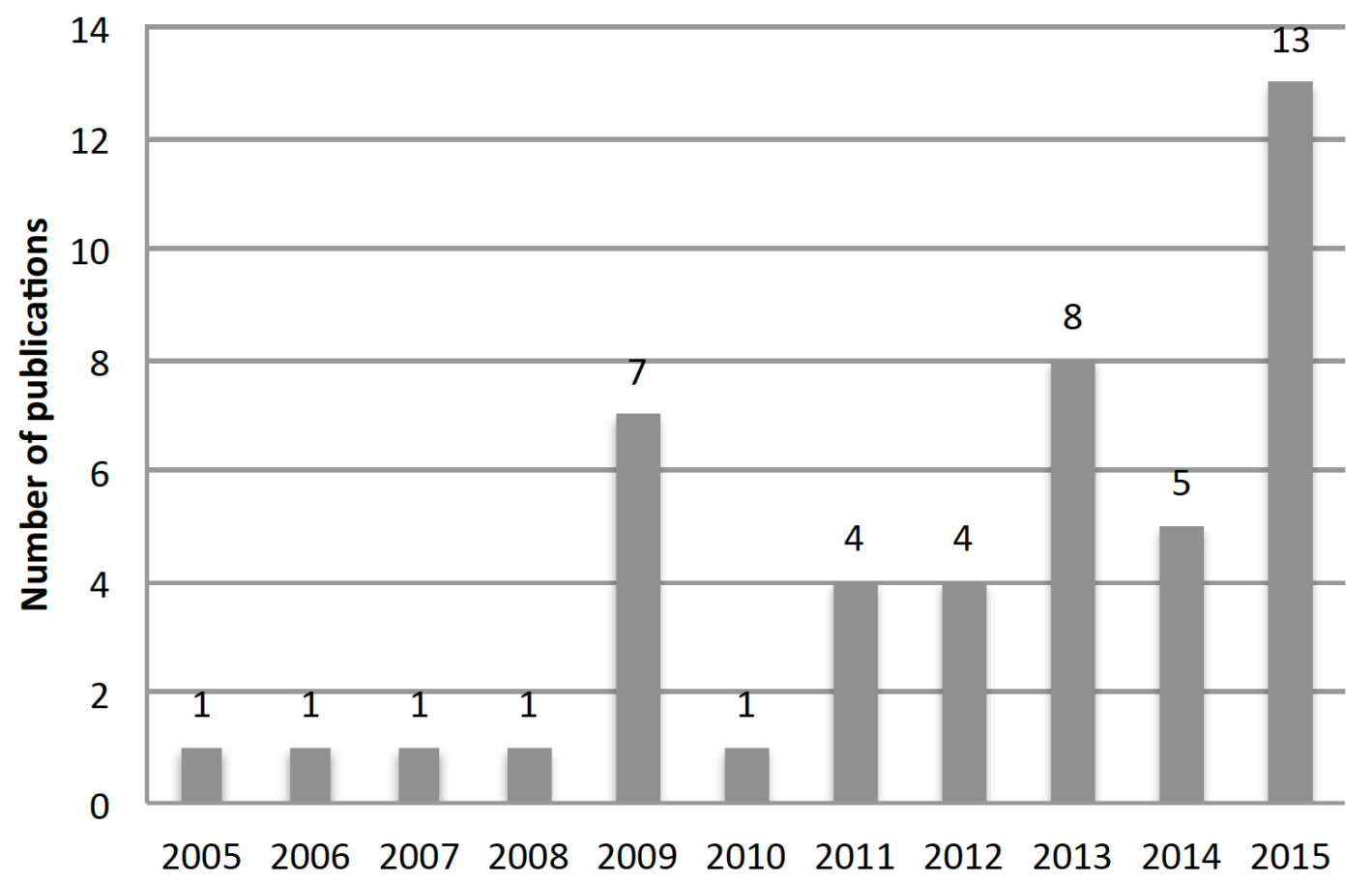

Figure 3. Distribution of the selected publications with regards to value evaluation in PSS preliminary design

Shimumura and Sakao (2007) are among the firsts to explicitly develop a method for service evaluation in a PSS context. Their service modelling approach set the basis for a further evolution of service engineering methods that focus on improving the effectiveness of the PSS development process (Shimomura and Arai, 2009). Shimomura and Arai (2009) have later describes "Service Engineering" as a design methodology providing methods and tools to increase the effectiveness of PSS development. They recognize the need to focus on the value generated by services, and propose the notion of "Receiver State Parameter" to model the satisfaction/dissatisfaction of customers or users. They further apply a set of tools to identify the most important contents and channels of the services, and use Quality Function Deployment (QFD) (Akao and Mizuno, 1994) to calculate the importance of both service functions and entities. Using the same logic Kimita et al. (2009) focus on enhancing the decision-making activity in preliminary design by providing an estimation of customer satisfaction in a conceptual stage. Differently from QFD, they introduce the use of non-linear functions to capture the correlation between quality and customers' satisfaction. A "Satisfaction-Attribute Function" is then determined as a result of regression analysis on a set of questionnaire data.

The challenge of modelling value of PSS is addressed also looking at the integration of such models in a Computer Aided Design (CAD) environment. Hara et al. (2009) demonstrate a modeling method for the functional representation of service for customer value, which is integrated in a CAD environment. This method is based on previous work on Service Explorer and Service Engineering and uses the functional representation of services together with an extension of the service blueprint to consider customer value in product design (Arai and Shimomura, 2004; Sakao and Shimomura, 2007). The service engineering concept is expanded by integrating the use of process and customer value simulations to support decision making by providing factual data; the work of Kimita et al. (2012), 
Pezzotta et al. (2015) and Rondini et al (2015) are recent examples of integration of simulations methodology for PSS evaluation in preliminary design.

Further works, not related to the Service Engineering concept, have addressed the research of IT support tools for value assessment in PSS preliminary design and the optimization of value through a mathematical function. For instance, Gautam and Singh (2008) propose a model that uses an optimization function to calculate customers' perceived value in case of design changes, using "serviceability" as one parameter. However, this approach is based on equations that rely on a number of assumptions (e.g., no market turbulences, flat ground competition, and necessity of decomposition of functions into physical part) that makes its practical use in a real scenario unclear.

Bertoni and Bertoni (2011) discuss value creation criteria, simulation techniques, and knowledge owners, to support PSS value simulation for aerospace components design. McKay et al. (2009) propose and integrated product, process, and rationale data models with the intention of providing through-life information for PSS. They further developed a software prototype, based on a bill of material structure and a digital definition of a product in a CAD system, with the intention of enhancing the management of knowledge in PSS projects. The same need is also addressed by Nemoto et al. (2015), who proposes a framework and a prototype system where PSS design knowledge is represented by five elements: Core product, Need, Function, Entity and Actor. Additionally, PSS literature highlights that understanding how valuable a PSS offer is in preliminary design embeds a certain level of uncertainty given by the limited information available. Herzog et al. (2014), have provided a first categorization of the type of the uncertainties and their potential impact. A more elaborated model, providing an assessment of the value of a PSS solution together with the evaluation of an "uncertainty score", is proposed in the ProVa method by Matschewsky et al. (2015), which is based on the PSS Evaluation method proposed by Sakao \& Lindhal (2012).

In recent years, an increasing focus on the capability to assess the value of a PSS solution is observed; either by simulation techniques or by providing a qualitative indication of the multifaceted aspects that plays a role in the final realisation of the PSS offers. For instance, some methods are designed to enable engineers to understand the effect that the provided service would have on customer value (e.g. Hara et al., (2009) or Shimomura and Sakao (2007)). Other methods focus more on the configuration of the engineering characteristics of a product that creates the highest value during its lifecycle (e.g. Isaksson et al., 2013 or Gorissen et al., 2014), often playing the role of enablers for knowledge-sharing or decision-making.

Figure 4 summarizes the number of selected publications per year that refers to the development or application of VDD methods that encompass service and operation aspects. In this case, hypothesis $\mathrm{H} 3$ ("the notion of Value Driven Design is trending in SE literature and addresses service aspects") cannot be fully verified, due to the limited number of publications obtained in the systematic literature review. 


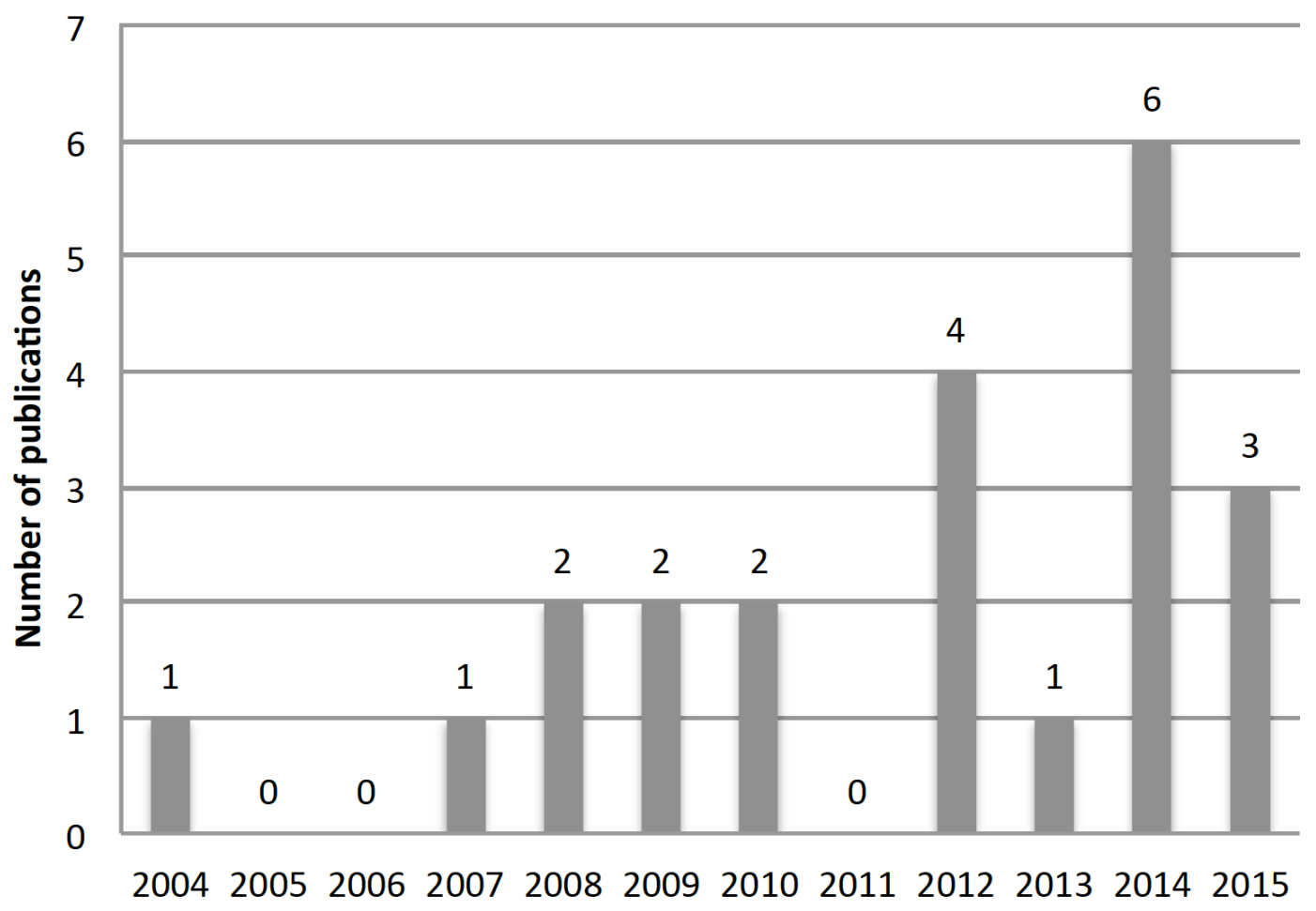

Figure 4. Distribution of the selected publications with regards to SE methods addressing value and service aspects

VDD is introduced with the objective to select the best set of technical capabilities to accomplish a mission, or a project, given some cost constraints. The Multi-Attribute Tradespace Exploration (MATE) approach proposed by Ross et al. (2004) is a milestone in the evolution of this concept. Even if Ross et al. (2004) do not make use of the VDD term, they share a set of fundamental goals that the following VDD methods and applications try to achieve. The lifecycle and operational value of a new system design is often captured by "ilities" (McManus et al., 2007; Hastings, 2014), which are defined by de Weck, et al. (2011, p. 66) as "desired properties of systems, such as flexibility or maintainability (usually but not always ending in "ility"), that often manifest themselves after a system has been put to its initial use”. From theory to practice, these properties are inherently difficult to quantify. Emergent behavior are likely to be predictable for simple systems, but when the latter grows in complexity it is not trivial to foresee in a conceptual design phase how a system will react against positive of negative changes in the surrounding context (Hasting, 2014).

In these earlier works, the value of a "system" is calculated based on the technical performances of the hardware, while service aspects and managerial implications are poorly considered in the value models (e.g., Castagne et al., 2009). While some authors claimed VDD to address cross-functionality and diverse teams, many existing case studies are strongly engineering-focused (Price et al., 2012). Cheung et al. (2008), for instance, propose the application of VDD in an initial study of an aerospace component, focusing on the characterization of an engine unit cost model coupled with the performance model. The academic discussion about VDD was revitalized by Collopy and Hollingsworth (2009) and has evolved in recent years to encompass a wider perspective. 
Curran et al. (2010) are the firsts to highlight the need to consider not only the value of basic economic drivers, but also the value for the customer and the value for the society, which will eventually result in economic impact. VDD is seen as a promoter of such main utility values, which are originally recognized and understood by the expert engineers but that — due to the complexity of both product and enterprise - tend to be fragmented into isolated requirements that result in lost control of the management of the desired system output (Curran et al., 2010).

The VDD research agenda published in 2011 (Soban et al. 2011) expand on the use of mathematical optimization functions to encompass questions of more general nature, such as "What is the nature of a value function?", "How many value functions are needed?" and "Who's value are we modelling?". Part of more recent VDD literature recognizes that the development of mathematical optimization functions is not the only way forward (Soban et al., 2011; Monceaux and Kossman 2012). Rather, researchers see the opportunity to expand the notion of "value-drivers" towards reinforcing early stages of design iterations and fostering communication and concurrent activities among customers, producers, and suppliers.

Table 2 summarizes some of the most relevant value-related methods used in the PSS and VDD domains as decision support in preliminary design. They are initially classified discerning between approaches that are product-, service-, or operation-oriented. They have been further classified as quantitative, qualitative, or semi-quantitative, based on the type of data they use in the calculation. Quantitative refers to methods that express defined quantity linked to a unit of measurement. Qualitative refers to methods that express the value of a product as a generic attribute with no significance to the data value itself, and semi-quantitative reflects a combination of the previous two. Note that all these methods consider a combination of product, service, and operations. However, they are distinguished from one another by having stronger or weaker orientation towards one of these aspects. 


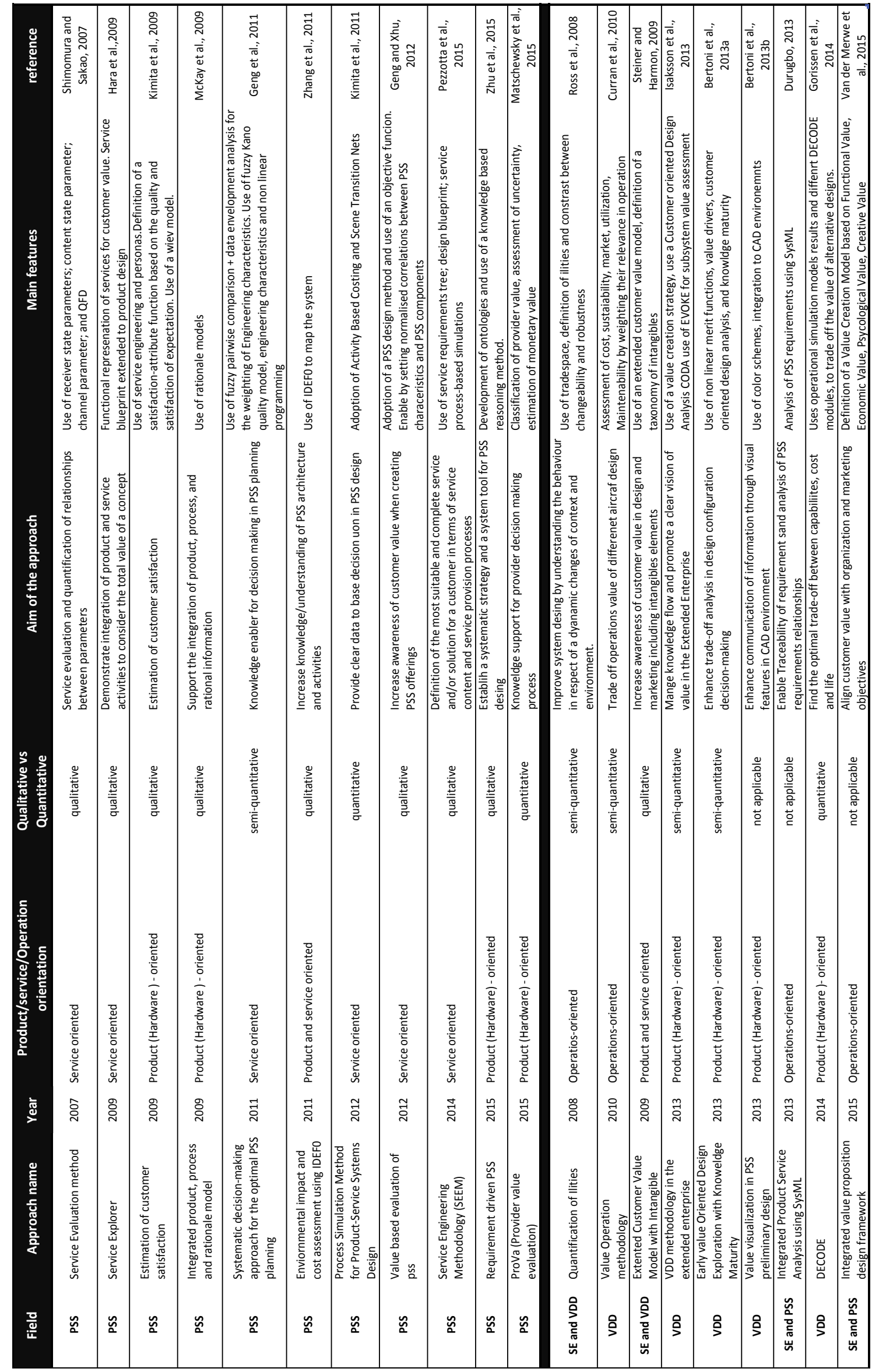




\section{VDD and PSS: a mutual learning opportunity}

The systematic literature review reveals that aims and features of PSS design and VDD research are converging towards a shared goal, and even towards shared industrial problem to be addressed. PSS literature shows a more mature focus and attitude towards evaluating the value contribution of the service components of a PSS offer, while VDD applications have evolved towards assessing the life-cycle effects on changing the engineering characteristic of a product. This section aims to point out the mutual learning opportunity existing by cross-pollinating the two domains, with regards to the opportunity of exporting existing methods and tools to the neighboring area.

\subsection{What can PSS design learn from VDD?}

\section{Learning 1: VDD can teach PSS decision-makers how to adopt a more hardware-oriented perspective during conceptual design.}

Sundin et al, (2009) observed that the increasing focus on service aspects in the design process means for manufacturers to include new objectives in their product development projects, stretching and stressing the requirements for the PSS hardware. Considering qualitative value assessment techniques used for requirements analysis and concept evaluation in PSS (Cavalieri and Pezzotta 2012)—such as, Pairwise comparison (e.g., Geng et al. 2010, Luczak et al. 2007), Analytic Network Process (ANP) (e.g., Geng et al. 2010; Lee et al. 2010) and Quality Function Deployment (QFD) (Lee and AbuAli 2011; Aurich et. A1. 2006) - problems are seen in the way value is related to hardware features of a PSS solution.

VDD research might teach PSS decision-makers how to adopt a more hardware-oriented perspective during conceptual design, and how to look at hardware attributes (mainly technical performance) as enablers for service provision. VDD research strongly focuses on the notion of "extensive attributes" (Collopy and Hollingsworth, 2011), which constitutes the basis for the creation of system and component value functions. Their definition recalls that of Product-based values as stated by Kowalkowski and Kindström (2009), although they do not explicitly contain sustainability aspects. They include performance, reliability, maintainability, safety, cost, and technical risk attributes. In VDD these attributes are coupled to an objective function, which is a scalar function that converts the team's full set of attributes into a score. The design team's task is to create a design that yields the highest score (while meeting all the requirements on the non-extensive attributes).

The empirical study shows that the integration of such attributes in the PSS design decision making process may provide designers with a framework to rigorously evaluate and compare different system concepts in the technical domain, using a unifying set of attributes in the value domain. It means that they can provide a structure for decision makers to understand the impact of different hardware design alternatives on the systems in which they are going to be integrated, rather than focusing on the design of the systems themselves. 


\section{Learning 2: Methods and tools for the analysis of "ilities" can support design teams in considering emerging behaviours during the PSS lifecycle.}

In its recent review Arnold Tukker (2015) spotlights that important new suggestions for the enhancement of PSS design methodologies include proposals for specific tools that could be used for requirement engineering and economic optimization. The latter must consider that in Usage Oriented business models, the PSS provider is responsible for the products' usability; therefore, it is even more important for the product to be easy to maintain (Azarenko et al., 2009). In addition, the frequency of use of the products favors a more durable design (Evans et al., 2007). Because the provider remains the products' owner, while the users change during the products' lifetime, that easiness of upgrading and remanufacturing enables a longer lifetime for the product. Other dimensions pay a role in this respect, such as the scalability of the offer, etc. These notions are well known within the VDD community, where methods and tools for the analysis of so called "ilities" (which are Flexibility, Adaptability, Scalability, Modifiability, and Robustness) for maintaining system lifecycle value have been proposed since almost a decade (see: Ross et al. 2008). Tradespace parameterization of systems can be exploited in this respect to design PSS solutions that are robust. Tradespace plot may be used to display the PSS system designs on a Cost-Utility space, showing the resources required (cost) and value delivered (utility) for the systems in a concise format.

The analysis of the interviews with industrial practitioners suggests that one of the key motivations for proposing the use of tradespace exploration techniques in PSS design is the necessity to cope with the uncertainty regarding past and present factors affecting system value, which dominates the preliminary phases of the process. Tools from VDD research can help modeling and understanding the issue of changeability (e.g., Fricke et al., 2000) for systems of products and services. A changeable system can change to meet the "actual" and future preferences of stakeholders given improved information as it is revealed over time. Designing a changeable system is believed to be crucial in a dynamic environment characterized by very different life cycles for products, software and services. Interview respondents pointed out that it might take several years for a new product to be fully developed, tested in lab, validated and ready to enter into the market. Requirements for the hardware generated in the beginning of the project quickly become 'old' looking at them from a software and service perspective, so planning for 'changeability' in the design is crucial to respond to the inevitable change in the future system context. In this way PSS may become capable of adapting to changes, being both designed to be expandable/scalable, able to accommodate growth in capability or emerging technologies, and to be effective, affordable and sustainable over their lifecycle.

Learning 3: VDD models can support quantification of sustainability improvements linked to PSS.

PSS have long been recognized as a major path towards sustainability (e.g., Mont 2002). Still, for PSS provider sustainability considerations are not the only concerns: rather sustainable PSS solutions must also turn into economic and competitive interest of the producer/provider (Vezzoli et al. 2015). The empirical study has pointed out that sustainability requirements are not discussed exclusively in design, but are rather traded-off with other requirements and judged in a context where more established engineering tools are used. Here, assessing and communicating 'sustainability' to technology developers may be difficult due to the problem of showing numbers and 'hard facts' related to the value generated by 
sustainability-oriented decisions. The answer lies in methods and tools that are able, already in an early design stage, to balance sustainability requirements with economic interests, highlighting how a sustainable design choice can create value for customers and stakeholders. Here, VDD is seen as a promising area from which to derive models to support the identification of win-win situations, where sustainable improvements are aligned with business advantages.

An opportunity is seen in the way sustainability-related choices may to the ability of generating cash-flows along the lifecycle of the PSS. In this respect, VDD research has long being working with Net Present Value (NPV) and Surplus Value (SV) models, and several examples of surrogate objects and functions that can be used to assess the long-term profitability of system alternatives are shown (Fanthorpe et al., 2011; Mullan et al. 2012; Price et al. 2012). The profitability idea is further cascaded down to the system components, and used to establish requirements at different levels of granularity in the system description. Still, while VDD does not yet consider sustainability explicitly in the value analysis (mainly due to the difficulty of translating it into monetary terms), recent attempts show how quantitative value assessments may be tighten up with qualitative sustainability analysis (Hallstedt et al. 2015; Bertoni et al., 2015). While still in tis infancy, the approach shows how VDD tools may be used to decompose and clarify sustainability implications and to compare them against performance-related capabilities already during preliminary design, by relating both to the overarching concept of 'value'.

\subsection{What can VDD learn from PSS design?}

\section{Learning 1: Methods and tools from PSS design can guide the definition of qualitative value criteria to extend current VDD models.}

VDD research stresses cost aspects (Brown et al. 2009). Paraphrasing Price at al. (2012), the use of cost equations engages all the stakeholders in a single design domain, so that the manufacturer can see the effect of their decisions on customers and stakeholders. For this reason, VDD research strongly focuses on the development of quantitative optimization models (e.g., Curran et al. 2010; Mullan et al. 2011, Cheung et al. 2012) able to account for the cost sustained by customers and users during the operational phase of the system. Monetary units are proposed in VDD as the most convenient, practical, and universally understood metric for value regarding revenue-generating products (Collopy and Hollingsworth 2011, Cheung et al. 2012, Curran, 2010).

However, recent contributions claim that quantitative monetary figures may diminish the potential use of the VDD methodology. Soban et al. (2011) in their research agenda propose then the use of a more subjective definition of value, and more qualitative assessment means because relevant value aspects (e.g. brand acknowledgement, knowledge reuse) cannot be monetized in a meaningful way. A main drawback is that early stage models are built on knowledge with a low degree of confidence, meaning that the VDD model outputs may lack of trustworthiness. This move is in line with the introduction of a S-D logic: a multitude of "intangible" customers value aspects (e.g., related to the end user experience with the product-service) may not be simply monetized quantitatively (Steiner and Harmon, 2009). 
The case study analysis shows that the emphasis on service elements brings the difficulty to evaluate aspects of value that are more difficult to estimate than performance metrics. In this context, design teams cannot just optimize a design because of the difficulty of building quantitative models to run optimization. The development of PSS requires designers to consider solutions that go beyond the improvement of hardware features, and that shall encompass lifecycle dimensions traditionally outside the technical horizon of engineers (Charnley et al 2011). Such extension suggests relying more on qualitative value assessment techniques. In this field SE practitioners may benefit from the experience matured in PSS design, where the "goodness of a design" (in the words of Cheung et al. 2012) is based on the change in degree of satisfaction of a receiver rather on the performances of the physical products (Sakao and Shimomura 2007). Receiver State Parameters and Function Parameters (Shimomura and Arai, 2009) are among the approaches proposed in Service Engineering literature to express receiver's state changes, and hence to assess value fulfillment with regards to end customers' satisfaction. Qualitative expressions such the above highlight another theme in the empirical study: when discussing quantitative methods, industrial practitioners point to the issue of 'understandability', and of the mathematical models

impeding 'conversations' while trying to make sense of their result and origin. Such theme is addressed in detail in the following section.

\section{Learning 2: PSS research can show how to improve communication among cross-functional design teams in Systems Engineering.}

Collopy (2012) spotlights the fundamental social nature of SE activities, and the importance of phenomena of social psychology, group dynamics and sense making. He recognizes that a single engineer does not design systems, components, or even parts. Instead, teams of engineers, often from multiple disciplines work together to design these artifacts. For a program involving the design of a complex system to be successful, communication must occur at all levels of the design, and during the time of the entire design cycle. Engineers must communicate both within their sub-systems, across to other subsystems at the same tier, and up and down the tiers, while program managers and leaders need to communicate amongst themselves as well as with their design teams, and with stakeholders.

PSS design has long been dealing with the issue of leveraging knowledge sharing and collaboration in cross-functional teams. The shift from the development of a hardware product to the development of a PSS ecosystem is a matter of creating a more integrated design process, fostering transdisciplinary knowledge sharing since the early phases (Johansson 2014). This often means expanding the VDD concept from its original formulation to formulate more plastic approaches where value models are intended to increase communication within the cross functional team, hence assuming the role of "coordinative artifacts" (Schmidt and Wagner, 2002) or "boundary objects" (Carlile, 2002). In particular, the opportunity to use such objects to better understand and resolve conflicts in stakeholder needs - a topic discussed in lean literature by Siyam et al., (2015) - is a significant improvement. Boundary objects have been defined as "objects that are both plastic enough to adapt to the local needs and the constraints of the several parties employing them, yet robust enough to maintain a common identity across sites" (Star and Griesemer, 1989, p.393). Using a value model as boundary object means that there is a shared communicative element that formalizes the value contribution of a design solution. To this extent value 
models play the role of enhancing the awareness about different lifecycle aspects of the new system, assuming the form of shared objects around which the discussions about value contribution could be staged. Value models are intended in this context to trigger negotiations, by forcing team members to assess their perceptions about the value of a design and to discuss where conclusions differ. In order to trigger conversation and negotiation VDD models need to be extended along two axes. Their "understandability" shall be leveraged by providing more contextual information about the underlying rationale of the model and the maturity of the information on which they are built ("i.e., where do the results come from?"). On the other end, guidelines shall accompany the model and suggest actionable course of actions (i.e., "what do we do with the results?"), which is about selecting which component to emphasize in the PSS offer (hardware, software, service?) so to render more value in the next VDD process iteration.

\section{Discussion: building a Value-driven PSS development methodology}

Based on the empirical studies and on the literature analysis, the authors have further detailed the PSS-VDD intersection to identify methods and tools to support the PSS innovation process with an outlook on value. The model proposed by Kennedy et al. (2008), which describe the innovation process at the company divided into two value streams - a Knowledge Value Stream (KVS) and a Product Value Stream (PVS) (Figure 5) — has been used as main reference in this activity (see: Isaksson et al. 2015). The first stream represents the capture and reuse of knowledge about markets, customers, technologies, products and manufacturing capabilities, which is general across projects and organizations. This activity is often known as R\&D, advanced engineering, or knowledge development. The latter is specific for each project and consists of the flow of tasks in what is often regarded as product development; people and equipment needed for creating, for example, drawings, bill of materials and manufacturing systems. 


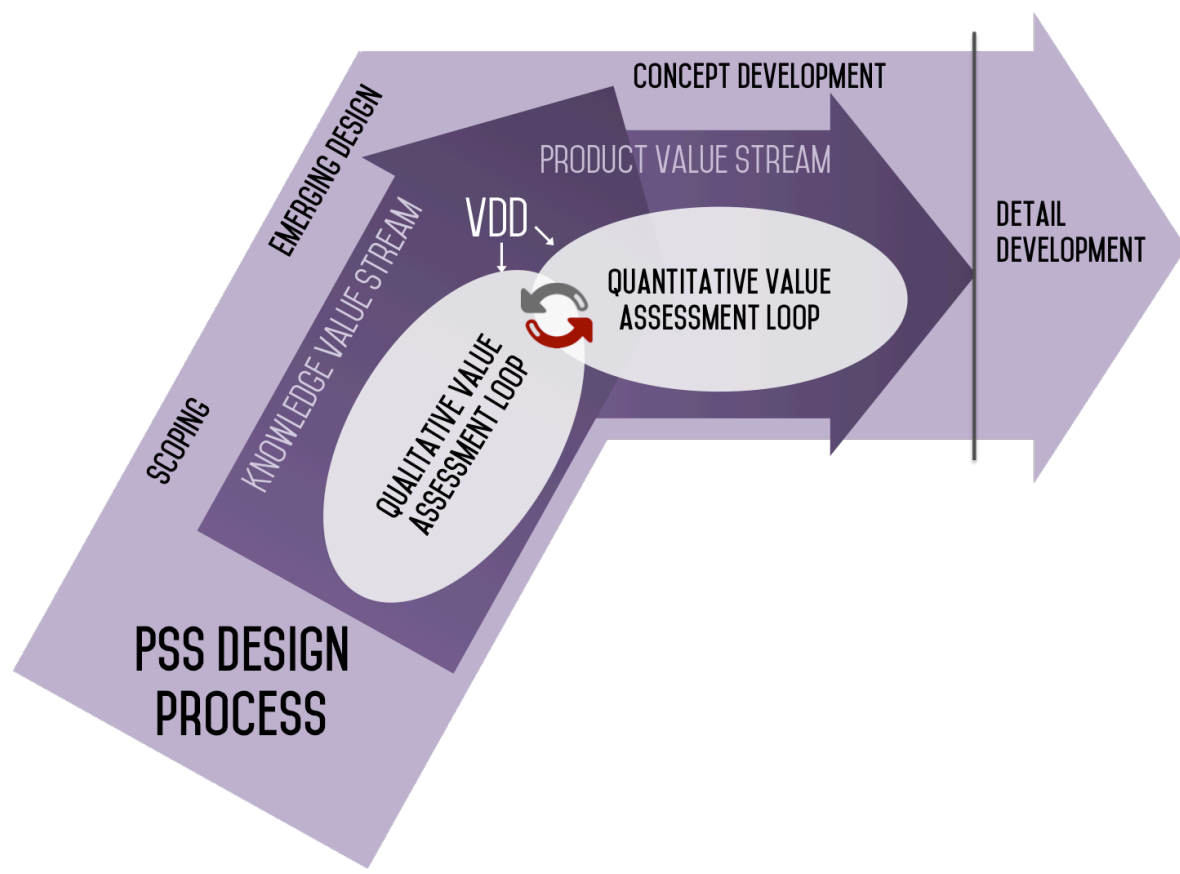

Figure 5: Knowledge vs. Product Value streams in the PSS design process and the role of quantitative and qualitative value assessment loops.

The findings show that the use of value models shall address both streams. It begins from the earliest phases of design, where the design problem is quite open: here the alternative technologies to explore as solutions are many and there is a need to understand broadly the potential implications of ways forwards. The problem space further recognizes the emerging design phases, where typically the engineering team has formulated concepts and begun modeling candidate solutions. Finally, the design space covers the more detailed phases of design, where the actual product and process are selected for detailing. Progressing along the two streams different needs are observable when considering decision support, and the problem is that the "early phase" needs to be decomposed, as one method does not fit all.

- In the so-called Scoping phase, value-based decision support shall enable the screening of candidate solution strategies with limited effort and time, typically in the order of hours. Also, it shall enable the design team to handle situations where the information available is scarce, immature and incomplete.

- At the Emerging Design stage, value-based decision support shall enable the design team to confine the design space and down select concepts from a range of possibilities. Iterations are executed within one or few days.

- During Concept development, value-based decision support shall enable a greater depth of analysis in the given contexts. Both product and process definitions exist and are being refined to minimize risk, cost and any other requirements compliance necessary. The time frame for decision support tools is still time constrained; yet studies may now expand to weeks, and also the quality of the data available generally increases,

The proposed methodology is at the basis of the development of decision support enablers both for qualitative and quantitative value assessment. Demonstration of such enablers has been conducted in 
several cases studies in heterogeneous industrial sectors. Five demonstrators were developed and verified in the design of new technologies for commercial aircraft engines (see: Isaksson et al. 2013b; Bertoni et al. 2013). Two more demonstrators have been discussed with engineers and designers working for a multi-national road construction equipment manufacturer, in relation to the development of a middle joint for an asphalt roller. The aerospace context was particularly relevant concerning the impact on the product design given by the increasing offer of maintenance, repair and overhaul services. The road construction sector is characterised instead by an increased request of machine operating in different markets and conditions, and the selling of product service systems combinations to grant a continuous operational performance is increasingly perceived as important. Additional contexts of study were the development of a pipeline system (Khamukin et al., 2015) and an educational example related to the design of a bike wheel (Eres et al. 2014).

\subsection{VDD tools to enable the qualitative assessment loop}

EVOKE is a decision support tool, similar to QFD and inspired by the Concept Design Analysis (CODA) method (Wooley et al. 2001; Eres et al. 2014), which was developed in the context of the studied cases to model and simulate value in the qualitative assessment loop of the proposed methodology. EVOKE aims to provide a systematic approach to link customer and stakeholder needs to a product (composed of hardware and service) description, while maintaining a qualitative nature so to facilitate knowledge sharing across cross functional team members. Similarly to CODA, it maintains the correlation coefficients used in QFD - typically, strong (9), medium (3) and weak (1) - but replaces its linear numeric relationships with non-linear functions analogous to the Taguchi Loss Functions (Wadsworth 1997), which are minimization, maximization, optimization, and avoidance type. It further introduces a systematic approach (Weighing matrix) to produce rank-weight scores for customer and stakeholder needs, which are later used to aggregate the results of individual analysis in a unique value score. Table 3 lists the EVOKE-based demonstrators developed so far to support the design of subsystems and components intended to be part of the hardware for a PSS offer.

Table 3 List of case studies where EVOKE has been applied for sub-component design

\begin{tabular}{|l|l|l|l|l|l|l|}
\hline System & $\begin{array}{l}\text { Strategy for } \\
\text { value creation } \\
\text { (\# of system- } \\
\text { level needs) }\end{array}$ & $\begin{array}{l}\text { Targeted PSS } \\
\text { type (according } \\
\text { to Tukker 2004) }\end{array}$ & Sub-system & $\begin{array}{l}\text { Number of } \\
\text { design options } \\
\text { considered }\end{array}$ & $\begin{array}{l}\text { Model size (\# of } \\
\text { needs) vs. (\# of } \\
\text { engineering } \\
\text { characteristics) }\end{array}$ & $\begin{array}{l}\text { Total } \\
\text { intersections } \\
\text { (not blank) }\end{array}$ \\
\hline Aero-engine & $\begin{array}{l}\text { Emphasis on } \\
\text { operational } \\
\text { performances, } \\
\text { safety and } \\
\text { flexibility in } \\
\text { operation. (20) }\end{array}$ & $\begin{array}{l}\text { Result-oriented, } \\
\text { part of a Total } \\
\text { Care® offer }\end{array}$ & $\begin{array}{l}\text { Intermediate } \\
\text { compressor } \\
\text { case }\end{array}$ & $\begin{array}{l}3 \text { (one baseline + } \\
\text { 2 innovative } \\
\text { solutions) }\end{array}$ & (10) x (45) & $450(260)$ \\
\hline Aero-engine & $\begin{array}{l}\text { Emphasis on } \\
\text { operational } \\
\text { performances, }\end{array}$ & $\begin{array}{l}\text { Result-oriented, } \\
\text { part of a Total } \\
\text { Care® offer. }\end{array}$ & $\begin{array}{l}\text { Anti-ice solution } \\
\text { for air splitter }\end{array}$ & $\begin{array}{l}4 \text { (one baseline + } \\
3 \text { innovative } \\
\text { solutions) }\end{array}$ & $(15) \times(18)$ & $270(107)$ \\
\hline
\end{tabular}




\begin{tabular}{|c|c|c|c|c|c|c|}
\hline & $\begin{array}{l}\text { safety and } \\
\text { flexibility in } \\
\text { operation. (20) }\end{array}$ & & & & & \\
\hline Aero-engine & $\begin{array}{l}\text { Emphasis on } \\
\text { operational } \\
\text { performances, } \\
\text { safety and } \\
\text { sustainability } \\
\text { impact (20) }\end{array}$ & $\begin{array}{l}\text { Result-oriented, } \\
\text { part of a Total } \\
\text { Care } ® \text { offer. }\end{array}$ & $\begin{array}{l}\text { Anti-ice solution } \\
\text { for air splitter }\end{array}$ & $\begin{array}{l}4 \text { (one baseline }+ \\
3 \text { innovative } \\
\text { solutions) }\end{array}$ & $(28) \times(24)$ & $672(142)$ \\
\hline Asphalt roller & $\begin{array}{l}\text { Emphasis on } \\
\text { operational } \\
\text { performances } \\
\text { and } \\
\text { maintainability. } \\
(40)\end{array}$ & $\begin{array}{l}\text { Product } \\
\text { Oriented, one- } \\
\text { sale model with } \\
\text { emphasis on } \\
\text { maintainability } \\
\text { and spare parts } \\
\text { replacement. }\end{array}$ & Middle joint & $\begin{array}{l}4 \text { (one baseline }+ \\
3 \text { innovative } \\
\text { solutions) }\end{array}$ & $(21) \times(12)$ & $252(87)$ \\
\hline Bicycle & $\begin{array}{l}\text { Emphasis on } \\
\text { performances in } \\
\text { operation and } \\
\text { maintainability. } \\
(7)\end{array}$ & $\begin{array}{l}\text { Use-oriented, } \\
\text { part of a bike- } \\
\text { sharing offer. }\end{array}$ & Front wheel & $\begin{array}{l}3 \text { ( } 1 \text { baseline }+2 \\
\text { innovative } \\
\text { solutions) }\end{array}$ & $(5) \times(4)$ & $20(16)$ \\
\hline \begin{tabular}{|l|} 
Pipeline system \\
\end{tabular} & $\begin{array}{l}\text { Emphasis on } \\
\text { performances in } \\
\text { operation and } \\
\text { maintainability. } \\
(6)\end{array}$ & $\begin{array}{l}\text { Product } \\
\text { Oriented, one- } \\
\text { sale model with } \\
\text { emphasis on } \\
\text { maintainability } \\
\text { and spare parts } \\
\text { replacement. }\end{array}$ & - none - & $\begin{array}{l}\text { Entire design } \\
\text { landscape within } \\
\text { the system } \\
\text { boundaries. }\end{array}$ & $(6) \times(4)$ & $24(20)$ \\
\hline
\end{tabular}

\subsection{VDD tools to enable the quantitative assessment loop}

Quantitative demonstrators play with scenarios, and rely on NPV simulations, to learn about how product concepts will behave in the future, and how they will maintain their capability to deliver value under changing contextual conditions. The latter might relate, such as in the examples listed in Table 4, to changes in the intensity of environmental regulations, to changes in the price of materials, to changes in customer sensitivity towards sustainability, etc. Examples of such scenario-based quantitative value assessment models have been developed both in the aerospace domain, for the design of turbine rear structures (Bertoni et al. 2015), for the selection of the most suitable manufacturing process for a new aero-engine product (Hallstedt et al. 2015), and for the design of an asphalt roller sub system. All these scenarios are built from the perspective of the system being part of the "hardware" related to a PSS offer. 
Table 4. Case study application of quantitative value assessment models, features and targets

\begin{tabular}{|c|c|c|c|c|c|c|}
\hline System & $\begin{array}{l}\text { Scenario } \\
\text { creation }\end{array}$ & $\begin{array}{l}\text { Targeted PSS } \\
\text { type (according to } \\
\text { Tukker 2004) }\end{array}$ & Sub-system & $\begin{array}{l}\text { Number of } \\
\text { design } \\
\text { options } \\
\text { considered }\end{array}$ & Model type & $\begin{array}{l}\text { Sensitivity } \\
\text { assessment }\end{array}$ \\
\hline $\begin{array}{l}\text { Aero- } \\
\text { engine }\end{array}$ & $\begin{array}{l}\text { Based on } \\
\text { expected } \\
\text { operational } \\
\text { performances. }\end{array}$ & $\begin{array}{l}\text { Result-oriented, } \\
\text { part of a Total } \\
\text { Care } ® \text { offer. }\end{array}$ & $\begin{array}{l}\text { Turbine rear } \\
\text { structure }\end{array}$ & $\begin{array}{l}\text { Entire design } \\
\text { space within } \\
\text { the system } \\
\text { boundaries. }\end{array}$ & $\begin{array}{l}\text { Revenue } \\
\text { model }\end{array}$ & $\begin{array}{l}\text { Based on usage } \\
\text { patterns and fuel } \\
\text { consumption }\end{array}$ \\
\hline $\begin{array}{l}\text { Aero- } \\
\text { engine }\end{array}$ & $\begin{array}{l}\text { Based on } \\
\text { changes on } \\
\text { customers } \\
\text { sustainability } \\
\text { perception and } \\
\text { environmental } \\
\text { legislation. }\end{array}$ & $\begin{array}{l}\text { Result-oriented, } \\
\text { part of a Total } \\
\text { Care® offer. }\end{array}$ & $\begin{array}{l}\text { Manufacturin } \\
\text { g process }\end{array}$ & $\begin{array}{l}2 \text { (one baseline } \\
\text { and one } \\
\text { innovative } \\
\text { solution) }\end{array}$ & $\begin{array}{l}\text { Total Cost of } \\
\text { Ownership, } \\
10 \text { years }\end{array}$ & $\begin{array}{l}\text { Based the } \\
\text { process on } \\
\text { production lead } \\
\text { time and } \\
\text { availability } \\
\text { (Montecarlo } \\
\text { simulation). }\end{array}$ \\
\hline $\begin{array}{l}\text { Asphalt } \\
\text { roller }\end{array}$ & $\begin{array}{l}\text { Based on } \\
\text { customer } \\
\text { preferences in } \\
\text { different } \\
\text { geographical } \\
\text { regions. }\end{array}$ & $\begin{array}{l}\text { Product Oriented, } \\
\text { one-sale model } \\
\text { with emphasis on } \\
\text { maintainability and } \\
\text { spare parts } \\
\text { replacement. }\end{array}$ & \begin{tabular}{|l|} 
Middle joint \\
\end{tabular} & $\begin{array}{l}4 \text { (one baseline } \\
+3 \text { innovative } \\
\text { solutions) }\end{array}$ & $\begin{array}{l}\text { Total Cost of } \\
\text { Ownership, } \\
10 \text { years. }\end{array}$ & $\begin{array}{l}\text { Based on the } \\
\text { machine yearly } \\
\text { usage, usage } \\
\text { pattern and } \\
\text { resource } \\
\text { consumption. }\end{array}$ \\
\hline
\end{tabular}

\subsection{Reflections from the application of the proposed methodology}

The consideration of service-relevant aspects in the development of complex systems is becoming part of the everyday engineering trade-off analysis. Although not always directly referring to the PSS terminology, methods and tools for designing complex systems from a value perspective, encompassing the service dimension, are increasingly needed and discussed in SE. The proposed methodology for value-driven PSS development (Figure 5) generalizes some reflections about the crosspollination of the two domains.

It should be noted that quantitative and qualitative models are not mutually exclusive or sequential; rather they shall be used concurrently in continuous iterations as far as knowledge becomes available about problems and solutions. For instance, the development of the asphalt compactor middle joint exploits both the EVOKE matrix and an NPV model in an iterative fashion.

The case studies presented in Table 3 and Table 4 generated additional important lessons learned. Firstly, they have highlighted the importance of communicating the results of these models accurately. The capability of not overloading a designer or an engineer with too much information is regarded as essential for the effectiveness of the models: they shall be perceived as a support tool rather than increase the complexity of the working activity.

This asks for efficient and effective strategy for knowledge visualization. In this respect, the achievement of an improved "situation awareness" (Endsley, 1995; Simon, 1996), while wisely managing 
the number of "cues" presented to the decision makers (Severin, 1967), is a major discussion topics.. The use of color coded CAD models to visualize the value of an hardware in the frame of a PSS offer (Bertoni et al. 2013b) emerges from this discussion, and from observing that the use of computer-based support amplifies cognition of data (Card et al. 1999) and copes with the problem of information overload (Tegarden, 1999). Bertoni (2013) explains the benefits of using color-coded information to raise awareness of 'value' among engineers in design episodes. However, additional research is needed to understand the individual cognitive implications of such kind of visualization on designers' working habits, so to understand how a visualization approach can be most effective in the day-to-day working activities.

A major theme for VDD research is also how share knowledge about requirements and 'value' when collaborating across the supply network. Throughout the entire development process of complex product and service systems there is a broad spectrum of knowledge elements that need to be captured and stored in order to later be accessed, shared, and reused (Birkinshaw and Sheehan, 2002). Solutions to this problem need to consider both a technological and social perspective.

A feasible approach from a technological point of view is to treat the relevant models for value analysis as black boxes, i.e. sharing their location while exposing only the inputs of the models and allowing just the outputs of the calculation, without exposing its underlying mechanism or logic. The concept of black boxes imply that an object is viewed only in terms of its inputs, outputs and transfer characteristics without any knowledge of its internal workings, that is, its implementation is "opaque". In this context, web services can offer a feasible solution by allowing the client (a company that is part of the virtual enterprise) to access a value model (implemented by another company). During this interaction the following processes take place: 1) the server provides a well-defined interface - a Web Services Description Language (WSDL) document - of the value model to the client, 2) the client processes the WSDL document and provides the inputs required by the value model to the server, and 3) the server calculates the value and returns it to the client. In this overall process the knowledge on the internal workings of the value model is not exposed to the client.

From a social point of view, the codification strategy that characterises traditional knowledge management systems is found to be not fully effective when working across boundaries: however successful these systems may be for those who use it, they are limited by the context of the team or firm in which they are used (Vroom and Olieman 2011). This may not seem an issue for the organization, but it is an issue for the designers, because facts and experiences normally recorded in local databases within each company function are not visible at the time models need to be built. The so called "Second wave of knowledge management" (Mauritsen and Larsen 2005) tries to address this issues by focusing on the social infrastructure that allows the transfer of this knowledge and information across individuals. Research in PSS design has addressed these challenges focusing on the development of applications to support knowledge sharing across functions and organizations in a "lightweight" fashion, for instance through the concepts of Knowledge Enabled Engineering (Sandberg, 2005) and Engineering 2.0 (Larsson et. al. 2010). These applications have a twofold purpose: they aim at providing low-threshold mechanisms to codify experience and feedback from the individuals in the extended organization, and also at providing feedback mechanisms (e.g., comments, rating, likes, etc.) to stimulate a need to share 
knowledge among them. This contrasts with a CAD (Computer Aided Design), PDM (Product Data Management) or even a PLM (Product Lifecycle Management) logic, which is more closely coupled to the specific knowledge for solving product-specific problems and to a codification strategy.

\section{Conclusions}

The study shows that moving from a goods- to a service-dominant logic is a matter of being able to compare apples with apples when approaching the early stages of design. This requires the definition of a common denominator upon which solution alternatives can be benchmarked. While the notion of 'value' may provide such overarching metrics, this is easier said than done: 'value' is a context-dependent and multi-faceted notion, which needs to be reduced (i.e., rendered in more practical and actionable terms), to allow engineers to take decisions. The paper argues that:

- A VDD logic can teach designers how to approach value assessment, providing the methodological support to link this high-level notion of 'customer value' to the product/service characteristics, so to highlight and solve existing trade-offs;

- Techniques such as Tradespace exploration and Surplus Value analysis enriches the PSS designers' toolbox, so that value can be modeled in terms that are meaningful to those individuals taking early stage design decisions.

Still, VDD logic cannot just be forced to PSS engineers without considering the necessary integration with existing methodologies and tools. In this respect, both the literature study and empirical investigation show that there is room for improvement for VDD to incorporate more intangible and qualitative aspects in the assessment.

These reflections has brought to proposing an integrated methodology for Value-driven PSS design, which aims at synthesizing the leanings from both the PSS and VDD domain in a unique framework to support the design of Product Service Systems. Verification activities in heterogeneous case studies show that the necessary conditions and State-of-the-Art capabilities exist for combining research efforts into a multi disciplinary decision making environment. In particular the paper highlights that existing methods and tool can be used to bridge qualitative and quantitative aspects into a model based decision environment, both from an academic and an applied perspective.

However, it must not been forgotten that the purpose of introducing model-based support in early stage decision making is not that of replacing wisdom, but rather that of creating a better platform by which discussion about value can be kicked-off and grown. In a sense, such models play the role of 'boundary objects', triggering negotiations about what value means, and explaining to engineers why decision shall consider value as metrics instead of merely products or service requirements. It must be highlighted that the investigation of the role of value models as a boundary objects in cross-functional decision-making is still on an early stage, and little evidence exists today on of their effectiveness in design episodes. This is an important aspect driving present and future research. Experimental activities are currently on going to evaluate the effectiveness of value models as boundary objects in real design sessions. Ethnographic approaches (Anderson 1997) and protocol analysis (Gero and Mc Neill 1998), will be applied to analyze "how subtly, fluently and effortlessly designers negotiate common ground" (Larsson 
2003, p.156) through the use of value models. In parallel with these verification activities, future work will be also devoted to the study of knowledge management and visualization support for PSS and value modeling.

\section{Acknowledgements}

The research leading to these results has received financial support by the Swedish Knowledge and Competence Development Foundation (Stiftelsen för kunskaps- och kompetensutveckling) through the Model Driven Development and Decision Support research profile at Blekinge Institute of Technology. The work has also been performed with financial support from Swedish Governmental Agency for Innovation Systems (VINNOVA), in the frame of the NFFP \& VITUM project.

\section{References}

AIAA VDD committee. Value-Driven Design, [online], available at http://vddi.org/vdd-home.htm (accessed October 5, 2015)

Akao, Y., Mizuno, S. (1994). QFD: The customer-driven approach to quality planning and deployment. Asian Productivity Organization, Tokyo.

Alonso-Rasgado, T., Thompson, G., Elfström, BO. (2004). The design of functional (total care) products. Journal of Engineering Design, 16(6), 515-540.

Anderson, R. J. (1997). Work, Ethnography and System Design. Encyclopedia of Microcomputing. Vol. 20. pp. 159-183.

Arai, T., Shimomura, Y. (2004). Proposal of Service CAD System-A Tool for Service/Product Engineering Annals of the IRP, 53 (1), pp. 397-400

Aurich, J. C., Fuchs, C., \& Wagenknecht, C. (2006). Modular design of technical product-service systems. In Innovation in life cycle engineering and sustainable development (pp. 303-320). Springer Netherlands.

Baines, T.S., Lightfoot, H.W., Evans, S., Neely, A., Greenough, R., Peppard, J., Roy, R., Shehab, E., Braganza, A., Tiwari, A., 2007. State-of-the-Art in Product-Service Systems. Journal of Engineering Manufacture, 221 (10), 1543-52

Benedettini, O., Neely, A., \& Swink, M. (2015). Why do servitized firms fail? A risk-based explanation. International Journal of Operations \& Production Management, 35(6), 946-979.

Bertoni M, Bertoni A, Isaksson O, Amnell H, Johansson C, (2013a). Value-oriented concept selection in aero-engine sub-systems design: the EVOKE approach. In: Proc of the 23rd INCOSE International Symposium 2013, Philadelphia, PA

Bertoni, A. (2013). Analyzing Product-Service Systems conceptual design: The effect of color-coded 3D representation. Design Studies, 34(6), 763-793.

Bertoni, A., \& Bertoni, M. (2011). Assessing the Value of Product Service Systems Alternatives: A Conceptual Framework. Design Principles and Practices: An International Journal, 5(5), 655672.

Bertoni, A., Amnell, H., Isaksson, O. (2015). Value modelling in aerospace sub-system design: linking quantitative and qualitative assessment. In DS 80-2 Proceedings of the 20th International Conference on Engineering Design (ICED 15) Vol 2: Design Theory and Research Methodology Design Processes, Milan, Italy, 27-30.07. 15.

Bertoni, A., Bertoni, M., Isaksson, O. (2013b). Value Visualization in Product Service Systems Preliminary Design. In: Journal of Cleaner Production, Vol. 53, pp. 103-117.

Bertoni, M., Larsson, A., Ericson, Å., Chirumalla K., Larsson T., Isaksson, O. and Randall, D. (2012) The rise of social product development. International Journal of Networking and Virtual Organizations, 11(2):188-207.

Beuren, F. H., Ferreira, M. G. G., \& Miguel, P. A. C. (2013). Product-service systems: a literature review on integrated products and services. Journal of Cleaner Production, 47, 222-231.

Birkinshaw, J., \& Sheehan, T. (2002). Managing the knowledge life cycle. MIT Sloan management review, 44(1), 75 . 
Blessing, L.T., Chakrabarti, A. (2009). DRM: A Design Research Methodology. Springer London.

Brown, O. C., Eremenko, P., \& Collopy, P. D. (2009). Value-centric design methodologies for fractionated spacecraft: Progress summary from phase 1 of the DARPA System F6 program (AIAA 2009-6540). Reston, VA: American Institute of Aeronautics and Astronautics (AIAA).

Brown, O., \& Eremenko, P. (2008). Application of value-centric design to space architectures: the case of fractionated spacecraft. AIAA Paper, 7869, 2008.

Card, S.K., Stuart, K., Mackinlay, J.D., Shneiderman, B., 1999. Information Visualization: Using Vision to Think. Morgan Kauffman.

Carlile, P.R. (2002). A Pragmatic View of Knowledge and Boundaries: Boundary Objects in New Product Development. Organization Science 2002, 13 (4), 442-455.

Castagne, S., Curran, R., \& Collopy, P. (2009). Implementation of value-driven optimisation for the design of aircraft fuselage panels. International journal of production economics, 117(2), 381388.

Cavalieri, S., \& Pezzotta, G. (2012). Product-Service Systems Engineering: State of the art and research challenges. Computers in Industry, 63(4), 278-288.

Charnley F, Lemon M, Evans S. Exploring the process of whole system design. Design Studies 2011;32(2):156-179.

Cheung, J., Scanlan, J., Wiseall, S. (2008). Value Driven Design—an Initial Study Applied to Novel Aerospace Components in Rolls-Royce plc. Collaborative Product and Service Life Cycle Management for a Sustainable World, Springer London, 241-248.

Cheung, J., Scanlan, J., Wong, J., Forrester, J., Eres, H., Collopy, P., Hollingsworth, P.M., Wiseall, S., and Briceno, S. (2012). Application of Value-Driven Design to Commercial Aero-Engine Systems. Journal of Aircraft 49: 688-702.

Collopy P (2012) A Research Agenda for the Coming Renaissance in Systems Engineering. In: Proc. of the 50th AIAA Aerospace Sciences Meeting Including the New Horizons Forum and Aerospace Exposition, Nashville, 9-12 Jan 2012

Collopy, P.D., and P.M. Hollingsworth. 2011. "Value-Driven Design.” Journal of Aircraft 48 (3): 749759.

Cook, D.J., Greengold, N.L., Ellrodt, A.G.,Weingarten, S.R. (1997). The relation between systematic reviews and practice guideline. Ann. Intern. Med. 127 (3), $201 \mathrm{e} 216$

Curran, R. (2010). Value-Driven Design and Operational Value. Encyclopedia of Aerospace Engineering. John Wiley \& Sons.

Dahlgren, J.W. (2006). Real options and value driven design in spiral development. INCOSE 200616 th Annual International Symposium Proceedings, Orlando, Florida.

Davies, A. (2004), "Moving base into high-value integrated solutions: a value stream approach", Industrial and Corporate Change, Vol. 13 No. 5, pp. 727-756.

de Weck, O., Roos, D., Magee, C. (2011). Engineering Systems: Meeting Human Needs in a Complex Technological World. Cambridge: MIT Press.

Eisenhardt, K.M. (1989). Building theories from case study research. Academy of management review, 14(4), 532-550.

Endsley, R., 1995. Toward a theory of situation awareness in dynamic systems. Human Factors, 37(1), 32-64.

Eres, H, Bertoni, M, Scanlan, J. (2014). Mapping customer needs to engineering characteristics: an aerospace perspective for conceptual design. Journal of Engineering Design, 25 (1-3), 64- 87.

Erginel, N. 2010. "Construction of a fuzzy QFD failure matrix using a fuzzy multiple-objective decision model". Journal of Engineering Design 21 (6): 677-692.

EU Commission (2013) Final Report Summary - CRESCENDO (Collaborative \& Robust Engineering using Simulation Capability Enabling Next Design Optimisation). Available at: http://cordis.europa.eu/result/ren/140562 en.html

Fabrycky, W.J., and W.J. Blanchard. 1991. Life-Cycle Cost and Economic Analysis. Englewood Cliffs: Prentice Hall.

Forsberg, K. and Moog's H (1999,).System Engineering for Faster, Cheaper, Better. In INCOSE International Symposium (Vol. 9, No. 1, pp. 924-932).

Gautam, N, Singh, N. (2008). Lean product development: Maximizing the customer perceived value through design change (redesign). International Journal of production economics, 114(1), 313332.

Geng,X., Chu, X., Xue, D., Zhang, Z. (2010) An integrated approach for rating engineering characteristics' final importance in product-service system development, Computers \& Industrial Engineering 59 (4) (2010) 585-594. 
Geraldi, J., Maylor, H., \& Williams, T. (2011). Now, let's make it really complex (complicated) A systematic review of the complexities of projects. International Journal of Operations \& Production Management, 31(9), 966-990.

Gero, J., Mc Neill, T., 1998. An approach to the analysis of design protocols. Design Studies, 19, $21-61$.

Goedkoop, M., van Haler, C., Riele, H., Rommers, P., (1999). Product Service-Systems, ecological and economic basics. Report for Dutch Ministries of Environment (VROM) and Economic Affairs (EZ).

Goodman, L.A. (1961). Snowball sampling. Annals of Mathematical Statistics 32(1) 148-170.

Gorissen, D., E. Quaranta, M. Ferraro, B. Schumann, J. van Schaik, M. Bolinches, I. Gisbert, A. Keane, and J. Scanlan. 2014. "Value-Based Decision Environment: Vision and Application." Journal of Aircraft 51 (5): 1360-1372.

Hallstedt S., M. Bertoni, and O. Isaksson. 2015. "Assessing sustainability and value of manufacturing processes: a case in the aerospace industry." Journal of Cleaner Production, in press.doi:10.1016/j.jclepro.2015.06.017

Hara, T., Arai, T., Shimomura, Y., Sakao, T. (2009). Service CAD system to integrate product and human activity for total value. CIRP Journal of Manufacturing Science and Technology, 1(4), 262-271.

Harrison, Andrew. 2006. "Design for Service: Harmonising Product Design with a Services Strategy." In ASME Turbo Expo 2006: Power for Land, Sea, and Air, 135-43. American Society of Mechanical Engineers.

Hastings, D., (2014). Value-Driven Analysis of New Paradigms in Space Architectures: An Ilities-Based Approach.

Hazelrigg, G. (1998). A Framework for Decision-Based Engineering Design. Journal of Mechanical Design 120 (4): 653-658.

Herzog, M., Meuris, D., Bender, B., \& Sadek, T. (2014). The nature of risk management in the early phase of IPS 2 design. Procedia CIRP, 16, 223-228.

Isaksson O, Bertoni M, Hallstedt S, Lavesson N (2015) Model Based Decision Support for Value and Sustainability in Product Development. DS 80-1 Proceedings of the 20th International Conference on Engineering Design (ICED 15) Vol 1: Design for Life, Milan, Italy, 27-30.07.15

Isaksson, O., Kossmann, M., Bertoni, M., Eres, H., Monceaux, A., Bertoni, A., Wiseall, S., Zhang, X. (2013). Value-driven design: a methodology to link expectations to technical requirements in the extended enterprise. In: Proceedings of the 23rd Annual INCOSE International Symposium 2013.

Isaksson, O., Larsson, T.C., Rönnbäck, AÖ. (2009). Development of product-service systems: challenges and opportunities for the manufacturing firm. Journal of Engineering Design, 20(4), 329-348.

Isaksson, O., Larsson,T.C., Kokkolaras, M., Bertoni, M. (2013b). Simulation Driven Design for ProductService Systems. In The Philosopher's Stone for Sustainability, edited by Y Shimomura and K. Kimita, 465-470, Heidelberg: Springer.

Johansson, C. (2014). Managing uncertainty and ambiguity in gates: Decision making in aerospace product development. International Journal of Innovation and Technology Management, 11(2), pp.21.

Johansson, C., Hicks, B., Larsson, A., \& Bertoni, M. (2011). Knowledge maturity as a means to support decision making during product-service systems development projects in the aerospace sector. Project Management Journal, 42(2), 32-50. doi: 10.1002/pmj.20218

Kennedy, M., Harmon, K., Minnock, E. (2008). Ready, set, dominate - Implement Toyota's Set-Based Learning for Developing Products and Nobody Can Catch You. Richmond: The Oaklea Press.

Khamuknin A.A., Bertoni, M., Eres, M.H. (2015) Avoiding Resonant Frequencies in a Pipeline Application by Utilising the Concept Design Analysis Method. International Conference on Engineering Design. July 27-30; Milan.

Kimita, K., Shimomura, Y., Arai, T. (2009). Evaluation of customer satisfaction for PSS design. Journal of Manufacturing Technology Management, 20(5), 654-673.

Kimita, K., Tateyama, T., Shimomura, Y. (2012). Process Simulation Method for Product-Service Systems Design. Procedia CIRP, 3, 489-494.

Larsson A. Making sense of collaboration: the challenge of thinking together in global design teams. In Proceedings of the 2003 international ACM SIGGROUP conference on Supporting group work 2003;9:153-160.

Larsson, A., Ericson, Å., Larsson, T., Isaksson, O. and Bertoni, M. (2010). Engineering 2.0: Exploring Lightweight Technologies for the Virtual Enterprise, in Randall, D. and Salembier, P. (ed) From CSCW to Web 2.0: European Developments in Collaborative Design, Computer Supported Cooperative Work, Springer-Verlag London, pp.173-191. 
Larsson, A., Ericson, Å., Larsson, T., Isaksson, O., \& Bertoni, M. (2010). Engineering 2.0: exploring lightweight technologies for the virtual enterprise. In From CSCW to Web 2.0: European Developments in Collaborative Design (pp. 173-191). Springer London.

Lee, H Kim, C., Park, Y (2010) Evaluation and management of new service concepts: an ANP-based portfolio approach, Computers \& Industrial Engineering 58 (4) (2010) 535-543.

Lee, J., \& AbuAli, M. (2011). Innovative Product Advanced Service Systems (I-PASS): methodology, tools, and applications for dominant service design. The International Journal of Advanced Manufacturing Technology, 52(9-12), 1161-1173.

Lightfoot, H., Baines, T., \& Smart, P. (2013). The servitization of manufacturing: A systematic literature review of interdependent trends. International Journal of Operations \& Production Management, 33(11/12), 1408-1434.

Löfstrand, M., Andrews, J., Karlberg, M., \& Karlsson, L. (2011). Functional product system availability: simulation-driven design and operation through coupled multi-objective optimisation. International Journal of Product Development, 13(2), 119-131.

Lovelace, K., Shapiro, D. L., \& Weingart, L. R. (2001). Maximizing cross-functional new product teams' innovativeness and constraint adherence: A conflict communications perspective. Academy of management journal, 44(4), 779-793.

Luczak, H. Gill,C., Sander, B. (2007) Architecture for service engineering - the design and development of industrial service work, in: Advances in Services Innovations, Springer, Berlin/Heidelberg, pp. 47-63.

Mathieu, V. (2001). Service strategies within the manufacturing sector: benefits, costs and partnership. International Journal of Service Industry Management, 12(5), 451-475.

Matschewsky, J., Sakao, T., \& Lindahl, M. (2015). ProVa-Provider Value Evaluation for Integrated Product Service Offerings. Procedia CIRP, 30, 305-310.

McKay, A., Kundu, S., de Pennington, A., Dawson, P. G. (2009). An Integrated Product, Process and Rationale Model for the Provision of Through-Life Information in Product Service Systems. In DS 58-8: Proceedings of ICED 09, the 17th International Conference on Engineering Design, Vol. 8, Design Information and Knowledge, Palo Alto, CA, USA, 24.-27.08. 2009.

McManus, H.M., Richards, M.G., Ross, A.M., Hastings, D.E. (2007). A Framework for Incorporating "ilities" in Tradespace Studies. AIAA Space 2007, Long Beach, CA.

Meier, H., Roy, R., Seliger, G. (2010). Industrial Product-Service Systems-IPS2 CIRP AnnalsManufacturing Technology, 59(2), 607-627.

Miller, D. and Hartwick, J. (2002), "The problem of solutions: balancing clients and capabilities", Business Horizons, March/April, pp. 3-12.

Monceaux, A., Kossmann, M. (2012). Towards a Value-Driven Design Methodology -Enhancing Traditional Requirements Management Enterprise. Proceesing of the 22nd INCOSE symposium, Rome.

Monceaux, A., Kossmann, M., Wiseall, S., Bertoni, M., Isaksson, O., Eres, H., ... \& Rianantsoa, N. (2014). Overview of Value-Driven Design Research: Methods, Applications, and Relevance for Conceptual Design. Insight, 17(4), 37-39.

Mouritsen, J., \& Larsen, H. T. (2005). The 2nd wave of knowledge management: The management control of knowledge resources through intellectual capital information. Management accounting research, 16(3), 371-394.

Mullan, C., Price, M., Soban, D., Murphy A. and Butterfield, J. (2011) An analytical study of surplus value using a Value Driven Design methodology, Aviation, Technology Integration and Operations (ATIO), American Institute of Aeronautics and Astronautics, AIAA 2011-6838, Virginia, U.S.A, 2011.

Nemoto, Y., Akasaka, F., \& Shimomura, Y. (2015). A framework for managing and utilizing productservice system design knowledge. Production Planning \& Control, (ahead-of-print), 1-12.

Ng, I., Parry, G., Smith, L., Maull, R., \& Briscoe, G. (2012). Transitioning from a goods-dominant to a service-dominant logic: Visualising the value proposition of Rolls-Royce. Journal of Service Management, 23(3), 416-439.

O’Neill, M. G., Yue, H., Nag, S., Grogan, P., \& de Weck, O. (2010, August). Comparing and optimizing the DARPA system F6 program value-centric design methodologies. In Proceedings of the AIAA Space Conference.

Pezzotta, G., Pirola, F., Pinto, R., Akasaka, F., Shimomura, Y. (2015). A Service Engineering framework to design and assess an integrated product-service. Mechatronics.

Price, M., Soban, D., Mullan, C., Butterfield, J., Murphy, A. (2012). A novel method to enable trade-offs across the whole product life of an aircraft using value driven design. Journal of Aerospace Operations, 1(4), 359-375. 
Qu, M., Yu, S., Chen, D., Chu, J., \& Tian, B. (2016). State-of-the-art of design, evaluation, and operation methodologies in product service systems. Computers in Industry, 77, 1-14.

Ravald, A., Grönroos, C. (1996). The value concept and relationship marketing. European Journal of Marketing, 30(2), 19-30.

Rehman, F.U. and Yan, X.T. (2011). Application of context knowledge in supporting conceptual design decision-making, International Journal of Product Development, 13(1): 47-66.

Reim, W., Parida, V., \& Örtqvist, D. (2015). Product-Service Systems (PSS) business models and tactics-a systematic literature review. Journal of Cleaner Production, 97, 61-75.

Rondini, A., Pirola, F., Pezzotta, G., Ouertani, M. Z., \& Pinto, R. (2015). SErvice Engineering Methodology in Practice: A Case Study from Power and Automation Technologies. Procedia CIRP, 30, 215-220.

Ross, A. M., Rhodes, D. H., \& Hastings, D. E. (2008). Defining changeability: Reconciling flexibility, adaptability, scalability, modifiability, and robustness for maintaining system lifecycle value. Systems Engineering, 11(3), 246-262.

Ross, A.M., Hastings, D.E., Warmkessel, J.M., Diller, N.P. (2004). Multi-attribute tradespace exploration as front end for effective space system design. Journal of Spacecraft and Rockets, 41(1), 20-28.

Roy, R. (2000). Sustainable product-service systems. Futures, 32(3), 289-299.

Royce W.W. (1970) Managing the Development of Large Software Systems, IEEE Press (August 1970) pp. $328-338$

Sakao, T., \& Lindahl, M. (2012). A value based evaluation method for Product/Service System using design information. CIRP Annals-Manufacturing Technology, 61(1), 51-54.

Sakao, T., \& Shimomura, Y. (2007). Service Engineering: a novel engineering discipline for producers to increase value combining service and product. Journal of Cleaner Production, 15(6), 590-604.

Sandberg, S. (2005). Knowledge Enabled Engineering. Luleå University of Technology.

Schmidt, K., Wagner, I. (2002). Coordinative artifacts in architectural practice. Fifth International Conference on the Design of Cooperative Systems (COOP 2002)/Cooperative Systems Design: A Challenge of the Mobility Age. Amsterdam, NL, IOS Press.

Schwandt, T.A., Lincoln, Y.S., Guba, E. G. (2007). Judging interpretations: but is it rigorous? trustworthiness and authenticity in naturalistic evaluation. New directions for evaluation, 2007(114), 11-25.

Severin, W., (1967). Another look at cue summation. Educational Technology Research and Development, 15(3), 233-245.

Shimomura, Y., Arai, T. (2009). Service engineering-methods and tools for effective PSS development. In Introduction to Product/Service-System Design (pp. 113-135). Springer London.

Shimomura, Y., Sakao, T. (2007). A Service Evaluation Method for Service/Product Engineering. Guidelines for a Decision Support Method Adapted to NPD Processes.

Simon, H.A., 1996. The Science of the Artificial. MIT Press, Boston.

Siyam, G.I., Wynn, D.C., Clarkson, P.J. (2015). Review of Value and Lean in Complex Product Development. Systems Engineering 2015.

Soban, D., Hollingsworth, P., Price, M. (2011). Defining a research Agenda in Value Driven Design: Questions that need to be asked. Proceedings of the 2nd International Air Transport and Operations Symposium, TU Delft, Netherlands.

Song, W., Ming, X., \& Wu, Z. (2013). An integrated rough number-based approach to design concept evaluation under subjective environments. Journal of Engineering Design, 24(5), 320-341.

Stacey, M., Eckert, C. (2003) Against Ambiguity. Computer Supported. Cooperative Work, 12, 153-183.

Star, S. L.; Griesemer, j. R. (1989) Institutional Ecology, 'Translations' and Boundary Objects: Amateurs and Professionals in Berkeley's Museum of Vertebrate Zoology, 1907-39. Social Studies of Science, 19, 387-420.

Steiner, F., Harmon, R. (2009). The Impact of Intangible Value on the Design and Marketing of New Products and Services: An Exploratory Approach. Proceedings of PICMET 2009. Portland, Oregon USA.

Sundin, E., Lindahl, M., Ijomah, W. (2009). Product design for product/service systems: design experiences from Swedish industry. Journal of Manufacturing Technology Management, 20(5), 723-753.

Tegarden, D.P., (1999). Business information visualization. Communications of the AIS, 1(4).

Tranfield, D. R., Denyer, D., \& Smart, P. (2003). Towards a methodology for developing evidenceinformed management knowledge by means of systematic review. British journal of management, 14, 207-222.

Tukker, A. (2004). Eight types of product-service system: eight ways to sustainability? Experiences from SusProNet. Business strategy and the environment, 13(4), 246-260. 
Ullman, D.G. (1992). The mechanical design process. New York: McGraw-Hill.

Van der Merwe, C. (2015). An engineering approach to an integrated value proposition design framework.

Vandermerwe, S., Rada, J. (1989). Servitization of business: adding value by adding services. European Management Journal, 6(4), 314-324.

Vasantha, G. V. A., Roy, R., Lelah, A., \& Brissaud, D. (2012). A review of product-service systems design methodologies. Journal of Engineering Design, 23(9), 635-659.

Vezzoli, C., Ceschin, F., Diehl, J. C., \& Kohtala, C. (2015). New design challenges to widely implement 'Sustainable Product-Service Systems'. Journal of Cleaner Production, 97, 1-12.

Vroom, R.W. and Olieman, A.M. (2011). Sharing relevant knowledge within product development, International Journal of Product Development, 14(1-4): 34-52.

Wadsworth, H.M. (1997). Handbook of statistical methods for engineers and scientists (2nd ed.). New York: McGraw-Hill Professional.

Waghmode, L. Y., \& Sahasrabudhe, A. D. (2012). Modelling maintenance and repair costs using stochastic point processes for life cycle costing of repairable systems. International Journal of Computer Integrated Manufacturing, 25(4-5), 353-367.

Whyte, W. F., Greenwood, D. J., Lazes, P. (1989). Participatory action research: Through practice to science in social research. American Behavioral Scientist, 32(5), 513-551

Wooley, M., Scalan, J., Eveson, W. (2001). Optimising the Development of a Medical Device Using Formal Engineering Design Techniques and the CODA System. Proceedings of the 27th International Conference on Concurrent Enterprising, 367-376.

Yin, R. (1994). Case study research: Design and methods . Beverly Hills.

Zhang, X.W., Auriol, G., Eres, H. and Baron, C. (2013). A prescriptive approach to qualify and quantify customer value for value-based requirements engineering, International Journal of Computer Integrated Manufacturing, 26(4): 327-345AIAA VDD committee. Value-Driven Design, 